$7-1-2013$

\title{
Leadership considerations for executive vice chairs, new chairs, and chairs in the 21 st century.
}

\author{
Elisabeth J.S. Kunkel \\ Thomas Jefferson University \\ Jon A. Lehrmann \\ Medical College of Wisconsin \\ Michael J. Vergare \\ Thomas Jefferson University \\ Laura Weiss Roberts \\ Stanford University
}

Follow this and additional works at: https://jdc.jefferson.edu/phbfp

Part of the Psychiatry Commons

Let us know how access to this document benefits you

\section{Recommended Citation}

Kunkel, Elisabeth J.S.; Lehrmann, Jon A.; Vergare, Michael J.; and Roberts, Laura Weiss, "Leadership considerations for executive vice chairs, new chairs, and chairs in the 21st century." (2013). Department of Psychiatry and Human Behavior Faculty Papers. Paper 35.

https://jdc.jefferson.edu/phbfp/35

This Article is brought to you for free and open access by the Jefferson Digital Commons. The Jefferson Digital Commons is a service of Thomas Jefferson University's Center for Teaching and Learning (CTL). The Commons is a showcase for Jefferson books and journals, peer-reviewed scholarly publications, unique historical collections from the University archives, and teaching tools. The Jefferson Digital Commons allows researchers and interested readers anywhere in the world to learn about and keep up to date with Jefferson scholarship. This article has been accepted for inclusion in Department of Psychiatry and Human Behavior Faculty Papers by an authorized administrator of the Jefferson Digital Commons. For more information, please contact: JeffersonDigitalCommons@jefferson.edu. 


\title{
Leadership Considerations for Executive Vice Chairs, New Chairs, and Chairs in the $21^{\text {st }}$ Century
}

\author{
Elisabeth J.S. Kunkel - Thomas Jefferson University
}

Jon A. Lehrmann - Behavioral Medicine, Dept. of Psychiatry and Behavioral Medicine Medical College of Wisconsin Milwaukee

Michael J. Vergare - Dept. of Psychiatry and Human Behaviour, Thomas Jefferson University, Philadelphia

Laura Weiss Roberts - Dept. of Psychiatry and Behavioral Sciences, Stanford School of Medicine, Stanford University Stanford

The need to fulfill academic goals in the context of significant economic challenges, new regulatory requirements, and ever-changing expectations for leadership requires continuous adaptation. This paper serves as an educational resource for emerging leaders from the literature, national leaders, and other "best practices" in the following domains: 1. Mentorship; 2. Faculty Development; 3. Promotion; 4. Demonstrating value in each of the academic missions; 5. Marketing and communications; and 6. Barriers

(see Table 1).

\section{Mentorship}

Mentorship is a critical skill of effective leaders (see Table 1) and is necessary for achieving the goals of today's academic department (1). The unique challenges of a psychiatry department make it difficult for a Chair (or Vice Chair) to get relevant mentoring from nonpsychiatric Chairs at one's home institution. Chairs of psychiatry at other institutions may be more useful as leadership mentors (2), especially given the expectation that a Chair should be competent to perform his/her job without significant training or assistance. Unfortunately, mentoring remains underrecognized and under-rewarded in the academic promotion system and in compensation models (3); often, it is not built into compensation models for Chairs and does not directly enhance departmental revenue.

Despite the above reservations, department leaders should identify mentors and should identify which leadership skill-sets/ tasks they should work on: finance; organizational dynamics; communication; practice management; recruitment and retention; and others. Peerto- peer mentorship should focus on clinical program development, educational innovation, and research collaborations.

The responsibility for faculty mentorship ultimately resides with the Chair: setting mission based performance benchmarks for mutually agreed-upon goals at the personal, departmental, institutional, and/or national level provides a clear, measurable set of expectations. In faculty who are disruptive, who underperform, or who don't meet the Chair's expectations, tailored interventions with more frequent check-ins are often needed.

Effectiveness mentorship benchmarks include: yearly faculty meetings with the Chair, faculty attainment of leadership positions, faculty recruitment and retention, faculty diversity, 
publications, awards, research funding, and leadership and faculty development program participation.

\section{Faculty Development for Leaders}

TheAAMC (American Association of Medical Colleges) offers a variety of leadership programs, (e.g., Executive Development Seminar for Associate Deans and Department Chairs). The AAMC highlights national programs under organizational leadership development on their website (http://www.aamc.org/initiatives/leadership/enter "national leadership development programs") (1). Other leadership training organizations are listed in Table 2. Paths to leadership also include the pursuit of additional degrees:

M.B.A., M.P.H., and Healthcare Administration.

Women in leadership who aspire to attain significant leadership roles should strongly consider the ELAM (Executive Leadership in Academic Medicine) program. ELAM offers personal and professional career guidance, as well as access to an extensive network of women physicians, dentists, scientists, and public health faculty. Women Executives in the Sciences and Healthcare (WESH; WESH was formerly known as SELAM [Society for Executive Leadership in Academic Medicine]) (2) is a national organization that offers networking opportunities, leadership training, and career guidance to women in leadership positions in academic medicine, healthcare, and the sciences.

The AACDP (American Association of Chairs of Departments of Psychiatry) helps interim Chairs, new Chairs, and Vice Chairs by providing mentorship, a forum for discussing leadership challenges, and an administrative fellowship for leaders destined to become Chairs. AACDP provides "A Tool Kit for New Chairs" (responsibilities, key issues, and resources) (4, 5), and can suggest Chairs who are willing to be mentors to new Chairs (4).

Executive coaches help refine the Chair's leadership package and are hired consultants who help develop leadership skill-sets: demonstrating accountability, communication, decision-making, goal-setting, dealing with organizational culture and politics, negotiation, developing innovative practices, personal career-planning, strategic planning, change-management, and others. The executive coach can be hired confidentially, can be retained as part of the institution's investment in the new Chair, or as part of a specific institutionally-sanctioned project. In order to advance, the emerging leader needs both a traditional curriculum vita, which highlights academic accomplishments, and an executive resume, which provides a summary of leadership accomplishments. Repeated self-assessment by the Chair and by his/her supervisors determines the next steps of the emerging leader's development. The Chair's leadership portfolio should reflect a balance of training and accomplishments on the job.

\section{Promotion}

The Chair should review rank and progress toward promotion against faculty promotion guidelines at the institution. Success of the individual academic faculty member relates to career focus, adequate faculty-development resources, academic products (publications, grants), and attention to mentorship. Chairs' support can assist rising faculty or can remediate areas of poor performance. The Department Chair should help faculty to network, to identify appropriate resources, to develop academic products, to define an area of intellectual and career academic focus, and to highlight their accomplishments. Meaningful individual connections with respected 
academicians sets the groundwork for subsequent letters of reference for promotion and academic collaborations. Lists of prominent organizations with relationships to psychiatry are available elsewhere (6). In one department, yearly "Promotions Bootcamp" was so successful in the numbers of psychiatry faculty being promoted that it was offered to nonpsychiatric faculty (see Table 3 ). Having a psychiatry representative on the university promotions and tenure committee is helpful.

Publications, attainment of programmatic benchmarks, and numbers of grants submitted or funded, can highlight the prominence of the department. Leaders can exert their influence inside and outside of the institution through committee and organizational leadership, national presentations and workshops, and publications with a high impact factor. "Report talk" highlights the department to the institutional hierarchy. Benchmarks to keep in mind for evaluating the leader's role in promotions include promotion timeliness and success, faculty presentations, and publications.

\section{Demonstrating Value in the Academic Missions}

\section{Benchmarks}

Benchmarks can provide a measurement of success in each mission.

Benchmarks for education include 1)MATCH results for the residency and fellowships; 2) percentage of medical students entering psychiatry; 3) where medical students match in psychiatry; 4) shelf examination scores; 5) number of fellowships; 6) publications by trainees; 7) trainee satisfaction; 8) rotation evaluations; 9) course evaluations; 10) PRITE scores; 11) ABPN pass rates; 12) presentations by trainees; 13) awards; 14) diversity of trainees; and 14) funding for trainees. Benchmarks for clinical operations include 1) volume of visits; 2) accounts receivable; 3 ) admissions; 4) insurance case-mix; 5) inpatient beds; 6) charges and receipts (amount, variance to budget, variance to previous year); 7) charge entry lag time; 8) collection ratio; 9) RVUs (relative value units); 10) cost-reduction efforts (e.g., reducing one-to-one observation); 11) new contracts; 12) time to new appointment; 13) patient satisfaction; 14) achievement of individual faculty targets; 15) transfer efficiency between medical-surgical services and psychiatry; 16) study or consultation turnaround time; 17) integrated-care models (centers of excellence); 18) performance-improvement measures; 19) percent occupancy; 20) average daily cen- sus; 21) breadth of specialty services; 22) adverse events; 23) market share; 24) Medical Group Management Asso- ciation (MGMA) standards; 25) no-show rates; and 26) geographic reach of the department.

Benchmarks for research include 1) publications (impact factor); 2) breadth/depth research portfolio; 3) original re- search (total direct costs, number of federally-funded grants); 4) number of grant submissions per year; 5) per- cent of funded submissions; 6) number of funded researchers; 7) non-federal funding; and 8) percent of institutional funding.

\section{Improving the Education-Valued Culture}

Improvement begins with an assessment of the current state of the department's educational components: undergraduate, residency, fellowship, faculty, and community. Leaders 
demonstrate their investment in the education by giving faculty regular feedback on the quality and value of their teaching. Salary and incentive issues are often in conflict with educational priorities. One option is to lower clinical productivity targets for faculty who do more educational service. Another option is to assign them clinical work in a higher revenuegenerating, more economically- efficient clinical setting. Because of limited institutional financial support for program directors and trainee education, the Chair often must offset education support with clinical revenues to meet salary expectations. Chairs have to decide the degree of financial transparency they want. Sharing all faculty-support sources (and amounts) makes yearly realignment of the budget much more difficult. Chairs should articulate which education activities bring money into the department.

Outside expert consultants (experienced Chairs or pro- gram directors) can conduct needsassessments via onsite reviews. The expert should meet with the department stakeholders to review results. Retreats can build consensus among department faculty and trainees. An educational re- treat can inform a SWOT (strengths, weaknesses, opportunities threats) assessment. The leader should measure educational benchmarks at baseline and after any interventions are delivered. Possible retreat outcomes (best facilitated with a post-retreat action plan) include the creation of specialty fellowships creation of a resident government structure, and/or the development of mission and vision statements. Faculty appreciate receiving awards for mentorship and the quality of education or receiving private or public recognition by the Chair for education- based activities. Positive feedback is an underutilized tool in a culture where constructive feedback is the norm (7).

Networking with leadership from community mental health agencies can foster relationships that subsequently form the basis for programmatic and contractual arrangements. A partnership with such agencies can lead to resident rotations; the agency would support resident salary lines and/or supervision in return for added service. Attention must be directed toward providing adequate supervision, malpractice coverage, salary support, and provider safety.

Finally, the Chair can require national presentations with a report out upon return. Putting national best-practices into action supports further collaborations, mentoring, and net- working. Providing travel funds to attend AADPRT (American Association of Directors of Psychiatric Residency Training) and ADMSEP (Association of Directors of Medical Student Education in Psychiatry) for faculty involved in residency and medical student education, respectively, also supports the education mission. The Chair should seek out other sources of faculty support at the institutional level (8).

\section{Improving a Department's Clinical Value}

Because psychiatry departments have fragile budgets with narrow margins and few moneymaking interventions, they depend on subsidization and contractual revenues to bolster clinical operations. Clinical revenues often cross- subsidize other missions. Behavioral health carve-outs and a time-burdened model of care create additional challenges in practice management. Liptzin and Meyer (9) report that academic health centers often engaged in lucrative contracts that included high fees for nonpsychiatric specialists but which excluded psychiatry. Engagement in the contracting process gives the department a voice in negotiations. Strategic contracting with 
payors should consider the competitiveness of the fee schedule, market share of the payor, and likelihood of garnering new referrals. Uniformity of faculty enrollment and participation in insurance panels makes assignment and triaging of new patients more efficient.

Clinical program support from the hospital, university, or institutional practice plan should be tied to returns on in- vestment as measured by specific targets. Targets should be determined collaboratively at the outset of the program support. Face-to-face strategic planning should supplement periodic data analysis. Strategic planning should be aligned with institutional priorities.

Contracts for clinical services are common in transplantation, pain, and bariatrics, where multidisciplinary participation is critical to programmatic success. The traditional liaison model is difficult to market because other departments do not see the value of support for nondepartmental faculty. Options for funding integrated-care models include a blend of fee-forservice revenues and percent full-time-equivalent (FTE) support models. Fee-for- service revenues usually are insufficient, given insurance barriers. Integrating psychiatry facult into service-line models (institutional clinical priorities) and/or centers of excellence should be tied to returns on investment. Mid- level providers can reduce overall costs. An understanding of the scope of practice and billing regulations for such providers must account for variation between states and insurance carriers.

Coordination of equitable clinical workload should be tracked in an organized fashion. Practice management involves setting realistic, achievable targets for individual faculty. Considerations for setting targets include site- specific richness of the payor mix, percent clinical FTEs, ability to generate bonus dollars in specific clinical set- tings, other nonclinical duties, ratio of base support to clinical revenue targets, and total salary. Responsibilities in the other academic missions need to be balanced with clinical priorities. Monthly productivity should be reported back to faculty; workload should be aligned with target expectations. Productivity can be bench- marked by the FPSC (Faculty Practice Solutions Center), which uploads data from academic health centers by provider, procedure code, physician, and specialty. Yearly RVUs, and other benchmarks are other alternatives. Productivity should be reviewed at the divisional and individual level.

Although providing high-quality, efficient, safe, and effective care is at the core of the clinical mission, assuring this level of care requires a proactive approach to analyzing and modifying how care is delivered; a robust performance- improvement process; and standardization of evidence-based practices. Quality and safety oversight are a necessary part of a Chair's toolkit. Safety measures include adverse events, suicides, homicides, elopements, ECT complications, and others. Quality measures include consultation turn-around time, sleep-study completion time, adherence to evidence- based practices, and others. For hospitals, length of stay (LOS), transfers to psychiatry, patient satisfaction, and hand-washing are more emphasized. LOS on inpatient psychiatry units, where reimbursement is per diem, may be less relevant. Psychiatric leadership is uniquely poised to enhance physician communication skills in order to improve HCAHPS (Hospital Consumer Assessment of Healthcare Providers and Systems) scores for the institution (10). In addition to a review of performance-improvement data and a response to sentinel events, 
the Chair needs to be proactive in overseeing the quality of care. Examples might include chart audits of variance from evidence-based practice in focused areas or touring of clinical sites to identify potential problems and/or examples of best practices. Barriers to the delivery of efficient, high-quality care include standardizing multiple individual practice styles and standardizing visit times, among others.

Finally, the Department Chair bears responsibility for implementation of the Electronic Medical Record (EMR). Privacy concern must be balanced with concerns for safety and the need for access across the multispecialty group practice (11). Firewall security and ability to re-strict access to protected information (e.g., psychotherapy notes) or to restrict access to sensitive information for vulnerable populations (psychiatric, drug and alcohol, and/ or HIV/AIDS) varies considerably across EMR platforms. Security is commonly inadequate. At the least, multi- specialty physicians should have access to medications and diagnoses.

\section{Improving a Department's Research-Valued Culture}

Research differentiates the academic department of psychiatry from other healthcare delivery systems. A successful psychiatric research climate depends on multiple factors: having a core of experienced, successful research faculty; a cohesive research strategy with focused priorities; adequate research infrastructure; availability of collaborators; attention to the research pipeline; and awareness of the national research agendas and emerging issues. The Chair needs to evaluate whether to invest more resources in clinical and/or basic science research, thereby defining a re- search agenda. A Chair should consider a research faculty recruitment strategy in negotiating a start-up package. A successful research strategy should consider that clinicians may see research as an imposition on patient care (12).

Faculty must know one another's work, and should have overlapping research interests in order to develop a culture of successful collaboration. Regularly scheduled research meetings can foster collaborative work and publications. Junior faculty who identify a research niche and a mentor are more likely to succeed. Some institutions encourage mentorship training for researchers (13). Few psychiatry departments can offer formal research training, so the Chair should consider faculty support to attend the annual Colloquium for Junior Investigators (14).

Few psychiatry residency graduates are established researchers. Although graduates learn research fundamentals during their residencies, they should pursue more intense research education to feed the research pipeline. One should recruit residency applicants who are interested in research to help develop this agenda. Information about an effective method for developing a research residency track was recently published (15). Encouraging faculty (and trainees) to be manuscript- and grant-reviewers also can help faculty develop research skills. Requiring a trainee research project helps promote the research culture. Public acknowledgment and appreciation of faculty who succeed in research provides positive reinforcement.

A strategic research approach includes a needs- assessment and/or retreat. Aligning research with the clinical strengths of a department supports the development of translational research. Faculty is more likely to carry projects through to completion if they are integrated with other academic pursuits. Departments should consider applications to several of the NIH 
Institutes, not just the NIMH (National Institute of Mental Health), as well as other federal agencies and foundations (9). Collaboration across departments and translational research are usually valued. The Chair must seek out a variety of ways to support research: collaboration with other funded investors, start-up funds for pilot grants, funding mechanisms other than just the RO1, foundations, charitable donors, etc. The psychiatry research portfolio can bolster the institution's and department's rank nationally. All departments need to have a critical number of research faculty to meet these benchmarks. Measures of success include the ability to negotiate a research startup package, successfully recruit and retain productive research faculty, and move the department's research ranking up the ladder over time.

\section{Marketing and Communications}

Chairs should not ignore the need to publicize faculty accomplishments in all of the mission areas. They should systematically identify and promote faculty for institutional and national awards. The American Psychiatric Association supports education awards for medical-student (Nancy Roeske Award) and residency (Irma Bland Award) education. Public recognition at an award reception enhances the value of the awards. It is important to consider diversity in nominations for awards. Responsibility for drafting nominations should be explicitly designated.

Marketing efforts should include monitoring and developing the department's digital footprint. The department website should include up-to-date highlights of faculty accomplishments and detail the breadth and depth of the academic programs. The website should be a portal for accessing training-program information and clinical services. A social networking site, if well-maintained, can augment the department's relationship with alumni and can provide updates on a real-time calendar of events. Outreach efforts through correspondence, social networking, national and local departmental, or institutional events can foster the relationships that are important in setting the foundation for fundraising and participation of alumni in the department. Although a fundraising tutorial is beyond the scope of this article, fundraising efforts need to be a systematic and intentional part of the Chair's efforts. Donors often direct their giving to specific clinical service needs, so fundraising considerations should be included in clinical strategic planning.

\section{Barriers}

Developing into a leader in psychiatry is not without great internal and external barriers. Internal barriers to becoming a Chair include inertia, satisfaction in one's current job, and fear of increased responsibility and the unknown. Personal and family considerations may limit the geographic scope of leadership positions under consideration. External barriers include institutional financial pressures; having a long-term, successful Chair with little chance to move up internally; having a Chair who is not interested in (or is even threatened by) the development of the faculty leaders; bias and prejudices within the institution's leadership; or simply a personality conflict with the Chair. Other barriers external to the Department include a Dean who is exclusively focused on 
hiring a Chair with very specific experience; having an unsupportive Dean; or being part of an institution that has cultural barriers. Lanier and Rose emphasize that the Chair should possess skills in four areas: clinical skills; educator abilities; academic accomplishments; and administrative or interpersonal skills (16). Application of the above value- added approaches gives a psychiatry leader a better chance at surmounting such barriers.

\section{Conclusions}

The authors encourage readers to use this article as a blueprint for evaluating their own leadership success and the value they add to the academic mission. The authors' goal is to help rising Vice Chairs understand the framework for leadership and to help Chairs review their own departments. Doing the right thing with individual faculty and "making the budget" are not sufficient for the success of the Chair. Leaders must bring inspiration and must communicate their vision enthusiastically. Success is measured by bench-marks and by the value added to the academic missions. Administrative leadership, business acumen, and social/ emotional intelligence are integral parts of the Chair's leadership portfolio. The Chair should promote a culture of diversity; academic freedom, and tolerance; creativity and productivity; and safe, effective clinical care. Chairs should support the education of competent, thoughtful trainees. A clearly-articulated, strategic research vision with talented faculty can lead to new discoveries that advance the field of psychiatry. Development of predictable, stable revenue sources should be aligned with goals of the institution at all levels (1).

\section{References}

1. Lee TT, Summergrad P: Leading academic departments of psychiatry. Acad Psychiatry 2011; 35:71-72PubMedCrossRefGoogle Scholar

2. Buckley PF, Rayburn WF: The care and feeding of chairs of departments of psychiatry. Am J Psychiatry 2010; 167:376-378 PubMedCrossRefGoogle Scholar

3. Mirin S, Summergrad P: The evolving academic health center: challenges and opportunities for psychiatry. Acad Psychiatry 2011; 35:89-95PubMedCrossRefGoogle Scholar

4. Munro S: A tool kit for new chairs. Acad Psychiatry 2006; 30: 301303PubMedCrossRefGoogle Scholar

5. Winstead DK: Advice for chairs of academic departments of psychiatry: the "Ten Commandments." Acad Psychiatry 2006; 30:298-300PubMedCrossRefGoogle Scholar

6. Munro S, Wilson DR: Psychiatry: organized and disorganized. Psychiatr Clin North Am 2008; 31:137-147 PubMedCrossRefGoogle Scholar 
7. Lehrmann J: Giving Feedback, in AAP Handbook of Career Development in Academic Psychiatry and Behavioral Sciences. Edited by Roberts LW, Hilty DM. Washington, DC, American Psychiatric Publishing, 2005, pp 147-155 Google Scholar

8. Haan CK, Zenni EA, West DT, et al: Graduate medical education leadership development curriculum for program directors. J Grad Med Educ 2011; 3:232235PubMedCentralPubMedCrossRefGoogle Scholar

9. Liptzin B, Meyer RE: Financing Academic Departments of Psychiatry. Acad Psychiatry 2011; 35:96-100PubMedCrossRefGoogle Scholar

10. Merlino JL, Coulton RW: Enhancing physician communication with patients at Cleveland Clinic. Group Pract J 2012; (Feb):24-32Google Scholar

11. Peterson D, Wickeham D: New challenge for academic psychiatry: the electronic health record. Acad Psychiatry 2011; 35:76-80PubMedCrossRefGoogle Scholar

12. Pato C, Abulseoud O, Pato M: The role of research in academic psychiatric departments: a case study. Acad Psychiatry 2011; 35:139-142PubMedCrossRefGoogle Scholar

13. Feldman MD, Huang L, Guglielmo J, et al: Training the Next Generation of Research Mentors: The University of California, San Francisco, Clinical \& Translational Science Institute Mentor Development Program. CTS Journal.com 2009, 2(3): 216-221Google Scholar

14. Balon R, Guerra E, Meador-Woodruff JH, et al: Innovative approach to research training: research colloquium for junior investigators. Acad Psychiatry 2011; 35:1114PubMedCentralPubMedCrossRefGoogle Scholar

15. Back SE, Book SW, Santos AB, et al: Training physician-scientists: a model for integrating research into psychiatric residency. Acad Psychiatry 2011; 35:4045PubMedCentralPubMedCrossRefGoogle Scholar

16. Lanier WL, Rose SH: The contemporary medical community: leadership, mentorship, and career choices. Mayo Clin Proc 2008; 83:974-977PubMedCrossRefGoogle Scholar 